\title{
A predictive maintenance method for products based on big data analysis
}

\author{
Shan Ren ${ }^{1, a}$, Xin Zhao ${ }^{2, b}$ \\ ${ }^{1}$ Engineering College, Honghe University, Mengzi, Yunnan, China \\ ${ }^{2}$ College of Life Science and Technology, Honghe University, Mengzi, Yunnan, China \\ a282952654@qq.com, b353435088@qq.com
}

Keywords: Predictive maintenance, PLM, IoT, R\&M, O\&M, big data, data mining

\begin{abstract}
Recently, withmanufacturing enterprises have begun to widely useadvanced information technology to real-time monitor of their business and product, a large amount of data related to product lifecycle were produced. Typical challenges for maintenanceunder the environment of big data is facing now are lacking of timely and accurate data of products, and lackingof useful pattern and knowledge of product lifecycle. To address this problem,in this research, by using the technologies of Internet of Things (IoT), anarchitecture of Research and Manufacturing (R\&M) and Operation and Maintenance (O\&M) process big data acquisition was proposed. Based on the R\&M and O\&M big data, a real-time decision making method for predictive maintenance was discussed, and the data flow model of predictive maintenance based on big data mining was also established.
\end{abstract}

\section{Introduction}

Product lifecycle management (PLM) is a new strategic approach to efficiently manage the product related information over the whole lifecycle. Its concept appeared in the late 1990s targeting the movement beyond engineering aspects of product and providing a shared platform for creation, organization, and dissemination of product related knowledge across extended enterprise [1]. Predictive maintenance is very important in PLM. It can help manufacturersto determine the condition of in-service product in order to predict when maintenance should be performed. It is believed an effective way to save cost and time, and to avoid unexpected equipment failures in manufacturing.

In general, product lifecycle consists of three phases: beginning of life (BOL), including design and manufacturing; middle of life (MOL), including use, service and maintenance; and end of life (EOL) where products are disassembled, remanufactured, recycled, reused, or disposed[2]. During BOL, product data is quite complete supported by enterprise information systems (EISs), such as computer aided manufacture design (CAD), enterprise resource planning (ERP), supply chain management (SCM) and manufacturing execution system (MES). However, during MOL and EOL, due to the ownership of the product is customer and there is no corresponding information support system, the data almost breaks down after the delivery of the product to the customer.As a result, actors involved in each lifecycle stages have made decisions based on incomplete and inaccurate product lifecycle information of other phases, which has led to operational inefficiencies [3]. This hinders the implementation of the true life cycle management.

Fortunately, with the rapid development of information and communication technologies, especially wireless technologies such as radio frequency identification (RFID), sensors, and smart tags. It is believed that these advanced technologies provide a promising prospect that enables lifecycle actors to track and analyse product lifecycle data, and make efficient decisions without spatial and temporal constraints [4, 5]. In 2004, the PROduct lifecycle Management and Information tracking using Smart Embedded systems (PROMISE) project[6, 7], firstly proposed the concept of closed-loop PLM. The intent of this project is to develop appropriate technology, software, and tools for decision making based on data gathered through a product lifecycle. Lee [8] proposed a ubiquitous product life cycle conception called UPLS system, which can obtain product lifecycle data and realize the information interaction at each stage.Georgiadis[9] studied predictive 
maintenance and remanufacturing application based on closed-loop PLM. For the problem of separating the physical product from the related product data in late phases of product lifecycle (e.g. use, maintenance and disposal), Erkayhan[10] presented use of RFID to manage product lifecycle data, so that generated product data can be read automatically and forwarded to different IT systems.

However, the application of emerging technologies brings new challenges. As companies began to widespread use advanced information technology to real-time monitoring and tracking of the business and product, a large amount of data related to product lifecycle are produced, such as product research and development $(\mathrm{R} \& \mathrm{D})$, manufacturing, usage, maintenance, recycling, etc. These data are increasing at an unprecedented speed, and presents the characteristic of big data.

Nevertheless, the application of big data technology in manufacturing, especially in PLM is very little. Many applications are focus on web analytics and customer behaviour analysis[11, 12].How to utilize the big data technology and advanced analysis method to make manufacturing more reasonable was analysed by Auschitzky[13]. Manufacturers taking advantage of advanced analytics can reduce process flaws, saving time and money.

Despite these progresses, the following challenges are still exist in traditional PLM under the big data era. The first challenge is how to establish an overall big data capturing and integration architecture to sense and exchange the real-time data during lifecycle. The second challenge is how to discovery the previously unknownand potentially useful patterns and knowledge from big data.

To address above challenges, in this paper, focus on research and manufacturing (R\&M) and operation and maintenance (O\&M) process of product lifecycle, architecture of R\&M and O\&M process big data acquisition is proposed, and the real-time usage status data of the product can be sensed and collected. Based on the R\&M and O\&M process data, a real-time decision-making method for predictive maintenance is presented, and the data flow model of predictive maintenance is also established.

\section{Architecture of product $R \& M$ and $O \& M$ process data acquisition based on IoT}

According to above ideas, the architecture of R\&M and O\&M processbig data acquisition based on IoTis constructed as shown Fig. 1.

Configuration of product embedded information devices (PEIDs). As seen in the bottom of Fig.1, configuration of the PEIDs isthe foundation of big data acquisition. In this architecture, PEIDs such as RFID tags and sensors are deployed to manufacturing things and products to real-time monitor and capture the usage status data of them.PEIDs stand for a'product embedded information devices' [2]. The term 'product embedded' implies that O\&M process datacan be tracked in a real time way over theMOL by embedding an informationdevice to a product itself.The term 'information device' indicates that thePEID can gather, process, and store data into itself.Inaddition, it may need a communication function toexchange data with external environmentsby itself. 


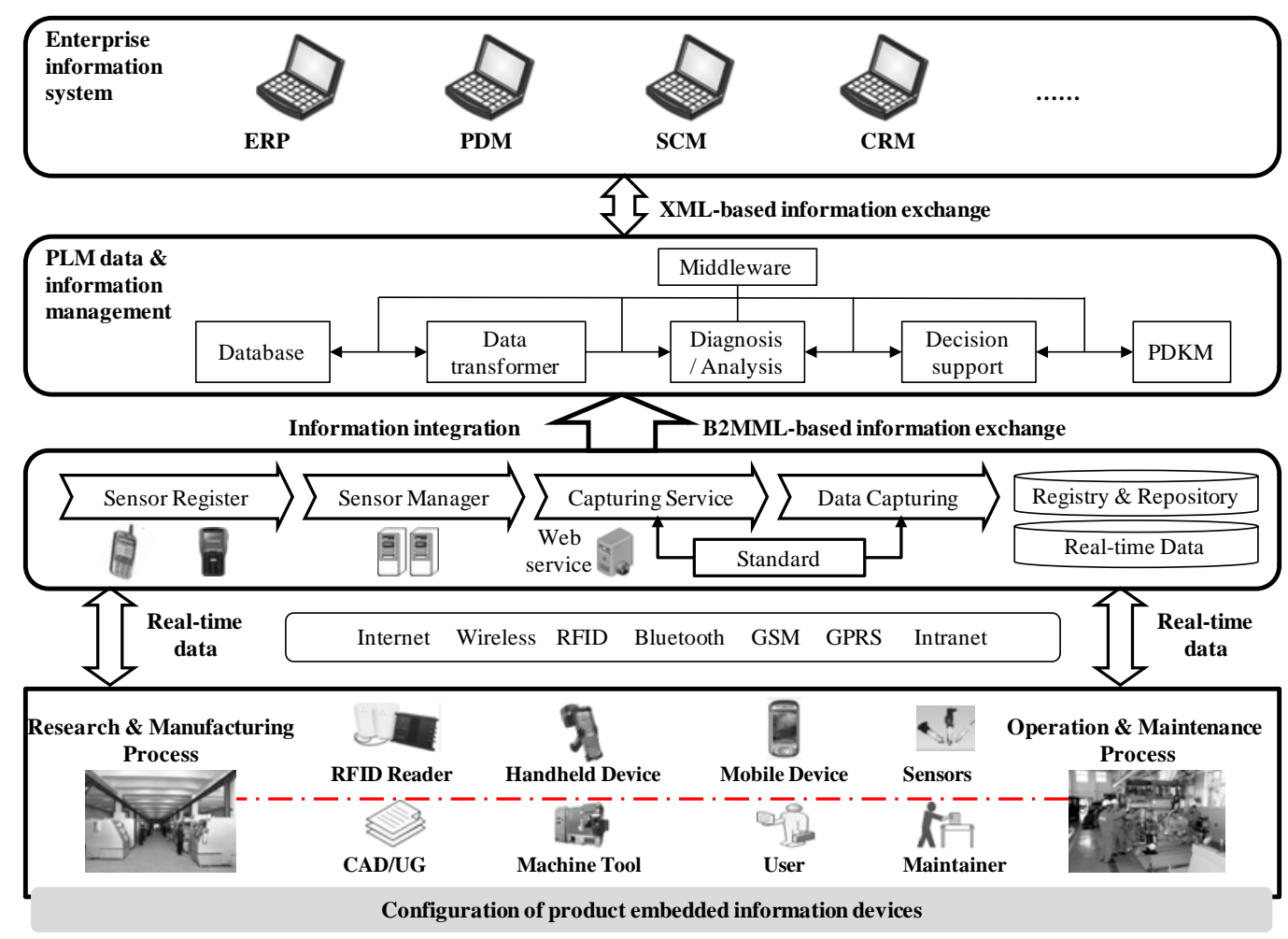

Fig. 1 Architecture of R\&M and O\&M processbig data acquisitionbased on IoT

Event perceptionand acquisition.Based on the configuration of the PEIDs, the real-time primitive event of the sensorsequipped to manufacturing things and products can be sensedand captured duringR\&M and O\&M process. When themanufacturing things and products come toa sensing area, the primitive event can be sensed by theregistered sensor. Through the communication protocoland relationships in the registry, the sensor can capture the data of the coming manufacturing things and products, and sent toIoT system. The communicationtechnologies such as internet, wireless, GPRS and intranet are used to build up the ubiquitous network environment for sharing the data.

Data integration and management.Databaseis used to store and manage data efficiently. Decision support system(DSS) provides lifecycle actors with thecapability to transform gathered data into necessary information and knowledge for specific applications. Product data and knowledge management (PDKM) managesinformation and knowledge generated during the productlifecycle. It is generally linked with decision support systemsand data transformation software. Middleware can be considered as intermediary between different software. Middlewareis important in the product lifecycle since it is the key technology to effectively gather and distribute PEIDsdata. It is used to support complex and distributedapplications, such asthe applications between RFID tags andbusiness information systems, to communicate, coordinateand manage data by transforming the data in anappropriate way.

\section{Real-time maintenance decision-making method of predictive maintenance}

During the daily use of a product,the usage data can be gathered to serve as animportant source of MOL information. After sometime of use, the product may need two kinds ofmaintenance. One is corrective maintenance when theproduct does not operate correctly owing to components failure or some other cause. The other ispredictive maintenance carried out aspart of a regular maintenance program while theproduct is still in good working order. This paper focuses on the predictive maintenance since it is an effective way tosave cost and time, and to avoid unexpected equipment failures in manufacturing.

Here, the decision is mainly basedon the abnormal events for the product such as abnormal temperature for bearings of turbine generators or abnormal vibration of machine tool 
spindle. It can be diagnosed, estimated and minedfrom field big data using prognostic algorithmsembedded in DSS periodically. These prognostic and classification data mining algorithms including: decision tree,k-Means, support vector machine (SVM),Apriori, kNN, Naive Bayes, and neural network. The basic rule ofpredictive maintenance is that if theabnormal events parameter value of the product reaches a certain threshold, it should bereplaced or repaired.

\section{Data flow model of product predictive maintenance based on big data mining}

Based on real-time capture the O\&M process data, and with the background of the PLM, the data flow model of product predictive maintenance is presented as shown Fig. 2.

Data flow model of product predictive maintenance. As seen in Fig. 2, after sometime of use of products (deployed with PEIDs) by users, the products may need maintenance.Through remote on-line monitor and diagnose,maintenance technicians can gather and analyse the O\&M process big data. If abnormal data or an abnormalevent is detected by maintenance technicians, then read and analyse the data that related to abnormal events. With the aidof data mining model and DSS, which analyse therelated MOL historical data, BOL data and real-time field data,predictive maintenance can enable the after-sale servicesection to predict when and which component mightbreak down and need to be replaced, and thus ensurethe product remains in good condition. New PEIDs are attached to new components or parts replaced. Forthose non-replaced components or parts, the residual life canalso be predicted. Thus the MOL information of theproduct item can be updated to PDKM and EISs.

Data and knowledge sharing mechanism based on big data mining. The data and knowledge are not only useful for corrective maintenance and predictive maintenance in the MOL phase, but also valuable for the BOL and EOL of product lifecycle. This section will illustrate how to utilizethe data mining result of O\&M process to provide the decision-making support for other lifecycle phases.

In order to perform the big data mining task, decisiontree, rough set theory, neural network,support SVM, association rulesandother hybridapproaches may been used to discover the knowledge and rules of MOL phase (e.g. usage pattern of product, maintenance history, customer support information, updated bill of materiel and updated product demand information). In the BOL phase, designers and productionengineers will receive feedback about detailed usage statusdata and knowledgeof product from maintenance/service engineers and customers. The feedback knowledge is extremelyvaluable for improvement of product design, reconfiguration of production system, efficient warehouse management and logistics optimization, due to designers and production engineers are able to exploitexpertise and know-how of other lifecycle actors to the individual stages of product lifecycle.

At the same time, the knowledge can been used by product recycle and reuse experts in EOL phase to product logistics or waste stream management, and product recovery decision making such as reuse, remanufacturing, material recycle and disposal and so on. 


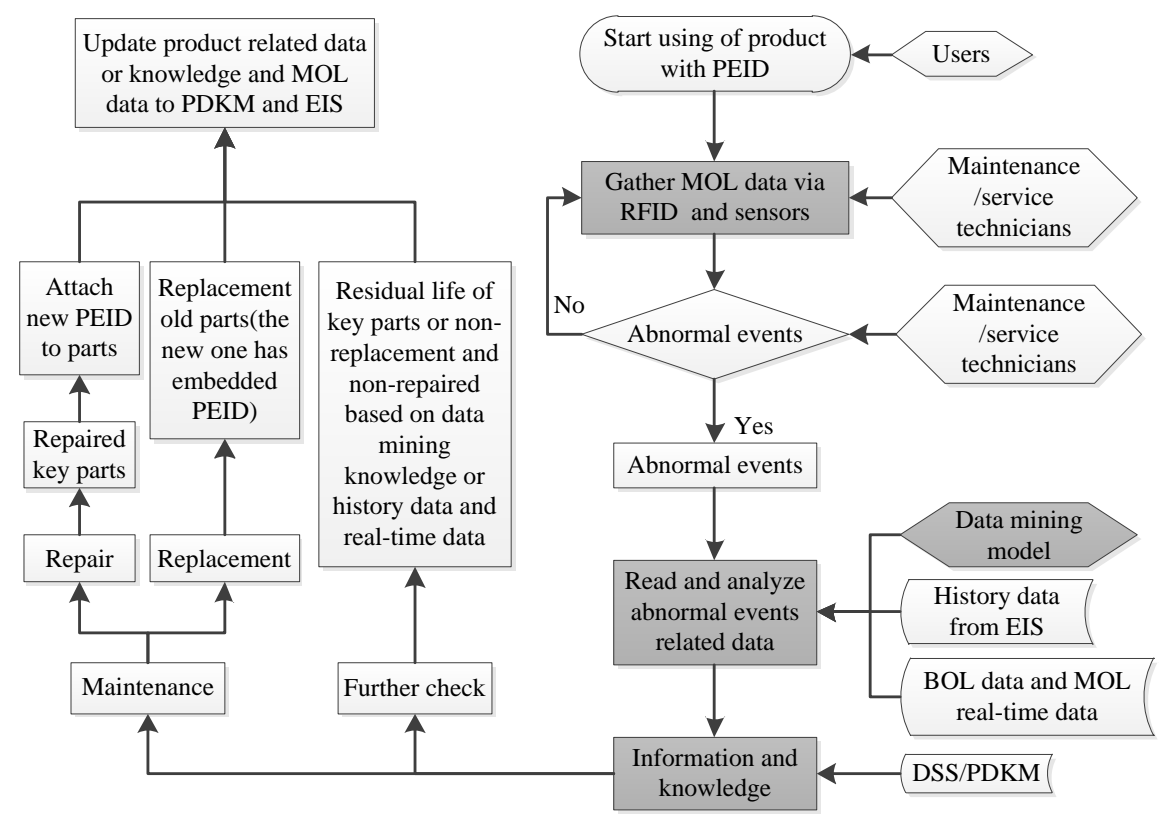

Fig. 2Data flow model of predictive maintenance

\section{Conclusions}

This study proposes an innovative concept of integratetraditional PLM with IoTand big data technology. Based on the IoT and big data miningtechnologies, an overall framework of R\&M and O\&M process big data acquisition is proposed. By establishing thesmart manufacturing and usageenvironment, the real-time O\&M process big data can be sensed and captured.Then, the real-time maintenance decision-making method is analysed, anda data flow model is presented to implement the data-driven predictive maintenance decision-making. The data and knowledge sharing mechanism of product lifecycle are also discussed.

\section{Acknowledgement}

Authors would like to acknowledge financial supports of Science and Technology Department Project of Yunnan Province in China (2013FD049), and the program of Hong he University (XJ15Y20).

\section{References}

[1] Jun, H. B., Shin, J. H., Kiritsis, D., \&Xirouchakis, P. System architecture for closed-loop PLM. International Journal of Computer Integrated Manufacturing, Vol.20(2007),p.684-698

[2] Jun, H. B., Kiritsis, D., \&Xirouchakis, P. Research issues on closed-loop PLM. Computers in Industry, Vol.58 (2007), p.855-868

[3] IMTI, Inc. Modeling and simulation for product lifecycle integration and management. Whitepaper. USA: IMTI, Inc. (2002)

[4] Holmström, J., Kajosaari, R., Främling, K., \&Langius, E. Roadmap to tracking based business and intelligent products. Computers in Industry, Vol. 60(2009), p.229-233

[5] Sallez, Y., Berger, T., Deneux, D., \&Trentesaux, D. The lifecycle of active and intelligent products: The augmentation concept. International Journal of Computer Integrated Manufacturing, Vol. 23(2010),p. 905-924 
[6] Jun, H. B., Shin, J. H., Kim, Y. S., Kiritsis, D., \&Xirouchakis, P. A framework for RFID applications in product lifecycle management.International Journal of Computer Integrated Manufacturing, Vol. 22 (2009),p.595-615

[7] Xu, D. F., Li, Q., Jun, H. B., Browne, J., Chen, Y. L., \&Kiritsis, D. Modelling for product information tracking and feedback via wireless technology in closed-loop supply chains. International Journal of Computer Integrated Manufacturing, Vol. 22(2009), p.648-670

[8] Lee, B. E., \&Suh, S. H. An architecture for ubiquitous product life cycle support system and its extension to machine tools with product data model. The International Journal of Advanced Manufacturing Technology, Vol. 42(2009), p.606-620

[9] Georgiadis, P., \&Athanasiou, E. The impact of two-product joint lifecycles on capacity planning of remanufacturing networks. European Journal of Operational Research, Vol.202(2010), p.420-433

[10]Erkayhan, S. The Use of RFID enables a holistic Information Management within Product lifecycle Management (PLM). InRFID Eurasia, 2007 1st Annual (p.1-4). IEEE (2007)

[11]Zhang, T., Sun, X., Chai, Y., \&Aghajan, H. Human Computer Interaction Activity Based User Identification. International Journal of Machine Learn-ing and Computing, Vol. 4(2014), p.436-449

[12]Zhang, T., Wong, K. B. Y., \&Aghajan, H. Concurrent activation events based trajectory propagation in smart environments. Journal of Ambient Intelligence and Humanized Computing, Vol. 5 (2014), p.867-880

[13] Auschitzky, E., Hammer, M., Rajagopaul, A. How big data can improve manufacturing. McKinsey Glob. Inst. http: // www. mckinsey. com/ insights/ operations/ how _ big _ data _ can _ improve_manufacturing 